
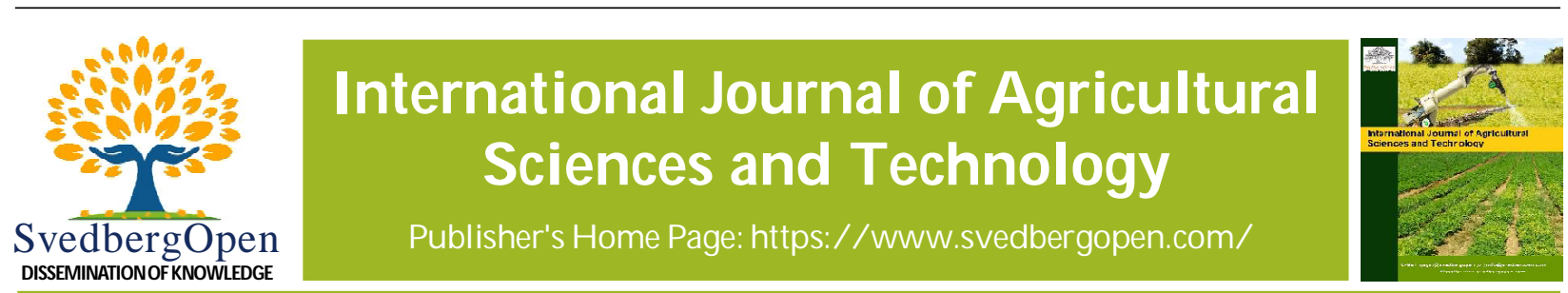

\title{
Influence of phytohormones on embryonic and vegetative growth of Caesalpinia crista
}

\author{
Hiral H. Sojitra ${ }^{1}$ and Jigna G. Tank ${ }^{2 *}$ \\ ${ }^{1}$ UGC-CAS Department of Biosciences, Saurashtra University, Rajkot, India. E-mail: hiralsojitra25@gmail.com \\ ${ }^{2}$ UGC-CAS Department of Biosciences, Saurashtra University, Rajkot, India. E-mail: jignagtank@gmail.com
}

\section{Article Info}

Volume 1, Issue 3, August 2021

Received : 19 March 2021

Accepted : 27 July 2021

Published : 05 August 2021

doi: 10.51483/IJAGST.1.3.2021.14-26

\begin{abstract}
Phytohormones are known to play crucial role in growth and development of plants. Effect of phytohormones is diverse in different plant species depending on its concentration, type of species and environmental factors where plant is growing. To know the influence of phytohormones on germination and vegetative growth physiology of Caesalpina crista present research work was designed. Initially seeds of Caesalpina crista were treated with different hormones Indole Acetic Acid (IAA), Gibberellic Acid (GA) and Benzyl Amino Purine (BAP)) and its effect on growth of embryo and tissue pattern formation was observed. Further, germinated plants were allowed to grow in soil and phytohormonal treatment was given at an interval of 15 days. Changes in vegetative growth physiology of plants were observed. On the basis of this analysis, it was concluded that Benzylaminopurine (BAP) treatment increases germination rate and shoot length of Caesalpina crista plants by promoting growth of pumule in embryo. IAA increases the leaf area and number of leaflets in plants. From the microscopic anatomical analysis of stem, it was observed that Although the number of vascular bundles were more in BAP treated plants, cambium activity was low as compared to GA and IAA treated plants. Endarch xylem differentiation was observed in GA and IAA treated plants whereas random xylem differentiation was observed in control and BAP treated plants.
\end{abstract}

Keywords: Caesalpina crista, Embryo, Phytohormones, Growth analysis

(C) 2021 Hiral H. Sojitra and Jigna G. Tank. This is an open access article under the CC BY license (https://creativecommons.org/licenses/by/4.0/), which permits unrestricted use, distribution, and reproduction in any medium, provided you give appropriate credit to the original author(s) and the source, provide a link to the Creative Commons license, and indicate if changes were made.

\section{Introduction}

Caesalpinia crista linn. is universally known as kanchak or Latakranja. It is a medicinal plant belonging to the family Fabaceae. It is found broadly throughout subtropical and tropical regions such as Asia, Australia, Indian Ocean Islands and Pacific Ocean Islands of the world. It is found in the hotter parts of India, Burma, Myanmar, Sri Lanka and Ceylon. It is predominantly found along the coastal areas of sea. In India, it is distributed in Gujarat, West Bengal, Kerala and Maharashtra. It is a moderate sized deciduous tree which grows in wild mostly in the deciduous forests. The leaves of this tree are bi-pinnate, nearly $1 \mathrm{~m}$ long, with the rachis armed with stout, sharp, recurved spines. The leaflets are oblong, number in 10 pairs, 2 to $5 \mathrm{~cm}$ long and are somewhat hairy. The flowers are yellow, born in axillary, simple or panicled raceme and about $1 \mathrm{~cm}$ long. The fruits are pods, oblong 5 to $7 \mathrm{~cm}$ in length, inflated and covered with slender spines and contain one or two seeds. The seeds are extremely bitter, commercially available in plenty at a very low cost and are widely used for treatment of diseases. The seeds are large, globular in shape, gray hard with a smooth shiny surface.

\footnotetext{
* Corresponding author: Jigna G. Tank, UGC-CAS Department of Biosciences, Saurashtra University, Rajkot, India. E-mail: jignagtank@gmail.com
} 
Each and every part of the plant is claimed to possess some therapeutic property. In Ayurveda, the seeds, leaves and bark of all three parts are used. The herb is useful for treatment of amenorrhea, dysmenorrhea, diabetes and intermittent fevers. Also, used as febrifuge, anthelmintic and expectorant (Das et al., 2010; Kirtikar and Basu, 1918; Handa and Kaul, 1996) its anthelmintic activity (Jabbar et al., 2007), nootropic activity (Kshirsagar, 2011), anti-oxidant and reactive oxygen species scavenging activity (Mandal et al., 2011), anticancer activity (Bodakhe, 2014), was already reported but the antidiabetic activity has not been established yet. The leaves, roots, and fruits of this plant are used as a tonic and an antiperiodic (Uphof, 1968). The seed kernels of C. crista displayed interesting antimalarial activity (Banskota et al., 2003). Its seeds are used as anthelmintic, antipyretic, anti-inflammatory, and antimalarial agent (Kalauni et al., 2001). The plant is a rich sources of cassane type furanoditerpenes, some of which have been reported to show antimalarial (Banskota et al., 2003; Linn et al., 2005), antiviral (Jiang et al., 2001), and anticancer (Patil et al., 1997)activities. Keeping in view the importance of this plant in human ailments present studies was designed to study the growth physiology of this plant in presence of different phytohormones.

Plant hormones are a group of organic substances which influence physiological processes mainly growth, differentiation and development of plant organs (Philosoph-Hadas et al., 2005; Kucera et al., 2005). For, e.g., Giberellic acid has germination promoting role as it has ability to overcome germination constraints that exist in seeds after fruit ripening (Metzger, 1983; Grappin et al., 2000), exposure to light and requirement of cold treatment (Hilhorst and Karssen, 1988; Derkx and Karssen, 1993; Yang et al., 1995; Toyomasu et al., 1998). The GAs can diffuse to aleurone and initiate a signaling cascade that leads to synthesis of á-amylases and other hydrolytic enzymes (He and Yang, 2013). These enzymes are secreted into the endosperm for degradation of storage compounds such as starch, lipid, and protein for development of seedling (Jacobsen et al., 1995; Bethke et al., 1997). GA has essential functions in stamen and anther formation (Nester and Zeevaart, 1988; Woodger et al., 2003), pollen formation, and pollen tube development (Singh et al., 2002; Kwon et al., 2015). Male sterility in flowers occurs due to malfunction of GA signaling during development of stamens and anthers (Kwon and Paek, 2016).

Cytokinins are synthesized in the roots and buds of plants. The effects of cytokinins include delay of senescence in mature leaves (Gan and Amasino, 1996). Cytokinins also induces flowering in certain plant species. It decreases dormancy period of axillary buds and some seeds. Higher concentrations of endogenous cytokinins are found in the embryos and developing fruits. The exogenous application of cytokinins stimulates release of axillary buds from apical dominance. Cytokinin antagonizes the effect of auxins. Cytokinins have effects on many physiological and developmental processes such as nutrient mobilization (Roitsch and Ehneß, 2000), apical dominance, the formation and activity of shoot apical meristem (Synková et al., 1997), floral development (Faiss et al., 1997) and the breaking of bud dormancy (Pospíśilová et al., 2000). Cytokinins act in many light regulated developmental processes like chloroplast differentiation (Wingler et al., 1998), the development of autotrophic metabolism (Mazid et al., 2011) and cotyledon or leaf expansion (Ma et al., 1998). Cytokinins are important regulators of environmental responses in plants. They execute their action via the molecular machinery of signal perception and transduction. The molecular mechanisms regulating different phytohormones synthesis and signaling, helps in modifying cytokinin synthesis pathways. These in turn helps in the generation of genetically modified plants with improved tolerance of abiotic stress (Peleg and Blumwald, 2011). Cytokinin activity has demonstrated wide variety of biological effects which includes changes in gene expression, inhibition of auxin action, stimulating of calcium flux the cell cycle, and as an anti stress and anti-ageing compound.

IAA is synthesized in the shoot apex and young leaves of plants. It is also synthesized in meristematic tissues, flowers, fruits and young seeds. Auxin has been shown to be essential for plant development mediating diverse responses, such as the control of senescence (Ellis et al., 2005), response to pathogens (Kazan and Manners, 2009; Wang and Fu, 2011), and abiotic stress (Wang et al., 2010). It is also involved in the regulation of apical dominance, phototropism, and epinasty. It also regulates fruit formation (De Jong et al., 2009) and leaf abscission (Rubinstein, 1963). Auxin promotes the establishment and maintenance of polarity, apical dominance, and tropic response to light or gravity (Woodward and Bartel, 2005; Vanneste and Friml, 2009). At the cellular level, it controls cell division (e.g., regulation of meristem formation giving rise to new organs such as lateral and adventitious roots) and cell elongation by altering cell wall plasticity. In addition, auxin is not only acting through linear pathways, but is also involved in many cross-talk responses with other phytohormones (Swarup et al., 2002; Vanstraelen and Benková, 2012). The most abundant endogenous auxin is IAA, which is able to fulfil most of the auxin actions involved in plant development and responses to the environment. To know the influence of phytohormones on germination and vegetative growth physiology of Caesalpina crista present research work was designed. Initially germinated seeds of Caesalpina crista were treated with different hormones (IAA, GA and BAP) and its effect on growth of embryo was observed. Further, germinated plants were allowed to grow in soil and phytohormonal treatment was given at an interval of 15 days. Changes in vegetative and anatomincal growth physiology of plants were observed. 


\section{Materials and methods}

\subsection{Seed germination}

Seeds of Caesalpinia crista were purchased from the local market. Dormancy of seeds was broken by boiling it in distilled water at $80^{\circ} \mathrm{C}$ for $2 \mathrm{~h}$. Further, seeds were allowed to soak in distilled water for $24 \mathrm{~h}$. Soaked seeds were tied in muslin cloth at room temperature of $25^{\circ} \mathrm{C}$ until they germinate.

\subsection{Treatment of germinated seeds with Phytohormones}

Germinated seeds were allowed to grow in presence of different phyhormones (Giberellic acid, Indole Acetic Acid and Benzyl amino purine) separately for a week. The concentration of each hormone used in experiment was $4 \mathrm{mg} / \mathrm{ml}$. Effect of phytohormones on growth of embryo was observed. The germinated seeds allowed to grow in distilled water were considered as control.

\subsection{Microscopic analysis of radical and pumule of embryo}

Here, germinated seeds were allowed to grow for two weeks in presence of each phytohormone separately. Transverse section of radical and pumule of control and phytohormone treated seedlings were taken with hand using sharp blade. These transverse sections were stained with phloroglucinol-HCL solution to stain vascular tissues. Each transverse sections were observed under Labomed light Microscope at 5X and 10X objective lens. Images were documented using Micaps image capturing software.

\subsection{Growth of germinated seeds in soil}

Germinated seedling of control and phytohormones treated Caesalpina crista Lin. were allowed to grow in soil up to maturity. Totally 40 plants were allowed to grow at botanical garden of Saurashtra University. Ten plants for control and 10 plant for each phytohormone treatment. Phytohormonal treatment was given to each plant at an interval of 15 days. Data on changes in the vegetative growth (shoot length, number of leaflets and leaf area) of plants was recorded at an interval of one month.

\subsection{Microscopic analysis of stem in six months old plants}

Transverse section of stem of six months old control and phytohormones treated plants were taken with hand using sharpe blade. These transverse sections were stained with phloroglucinol-HCL solution to stain vascular tissues. Each transverse sections were observed under Labomed light Microscope at 5X and 10X objective lens. Images were documented using Micaps image capturing software.

\section{Results}

\subsection{Changes in embryo development}

The germinated seed of Caesalpinia crista were allowed to grow for a week in presence of different phytohormones (Indole Acetic Acid (IAA), Gibberellic Acid (GA) and Benzyl Amino Purine (BAP)) separately. The germinated seeds allowed to grow in distil water were considered as control. The changes in growth of embryo in treated and non-treated seedlings were observed. Embryo was dissected out and size of embryo was compared. Maximum growth of embryo was inhibited in GA treated seeds as compared to control and other phytohormones. There was remarkable weak growth of pumule and radical in GA treated seedlings. In IAA treated seedling growth of pumule was promoted whereas growth of radical was delayed. In BAP treated seedlings, growth of radical and pumule both were equally promoted. The size of embryo was much larger as compared to control, IAA and GA treated seedlings (Figure 1).

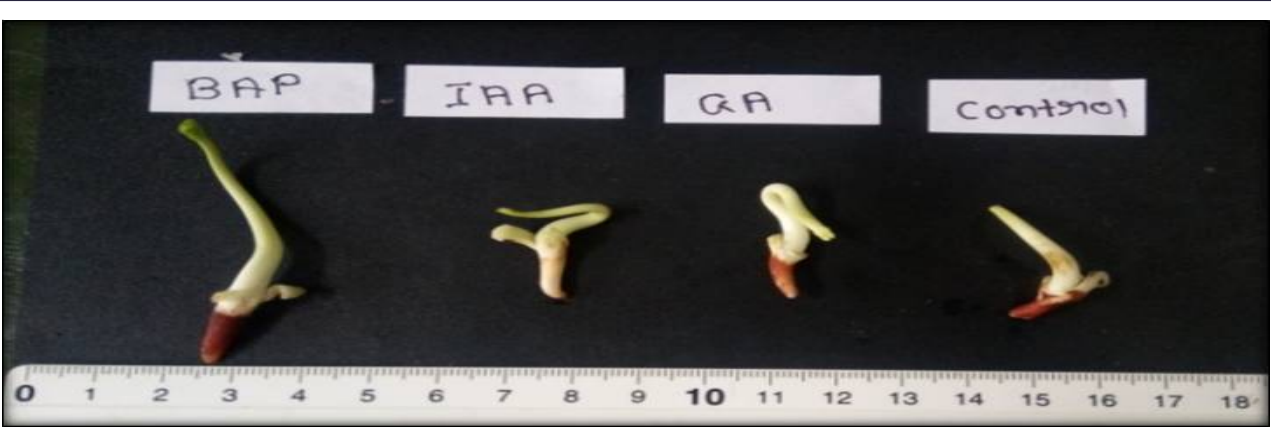

Figure 1: Effect of phytohormones on growth of embryo 


\subsection{Effect of phytohormones on tissue pattern formation of radical and pumule}

Transverse sections of radical and pumule of one week old phytohormones treated and non-treated seedlings were taken and observed under light microscope. From anatomical analysis of transverse sections of pumule it was observed that the broadness of the plumule was maximum in the GA treated embryo as compared to control, IAA and BAP treated embryo. The lowest broadness in plumule was observed in IAA treated embryo as compared to the control, BAP and GA treated embryo. The pumule of BAP and control were almost equal in broadness. The thick epidermis was observed in the plumule of IAA treated embryo compare to the control, GA and BAP treated plumule of embryo. The thin epidermis was observed in plumule of GA treated embryo compare to the control, IAA and BAP treated plumule of embryo. The maximum cortex region was observed in the plumule of GA treated embryo. While the minimum cortex region was observed in the plumule of IAA treated embryo. There was a notable change in number of vascular bundles formation in pumule of control and phytohormones treated seedlings. There were totally nine vascular bundles in T.S. of control pumule, 10 vascular bundles in T.S. of BAP treated pumule, 13 vascular bundles in T.S. of GA treated pumule, 15 vascular bundles in T.S. of IAA treated pumule. In vascular bundles development, maximum xylem and phloem differentiation was observed in GA treated seedlings whereas xylem and phloem differentiation was delayed in BAP treated seedling (Figure 2). The pith region was maximum in the GA treated pumule while minimum pith region was observed in IAA treated plumule.

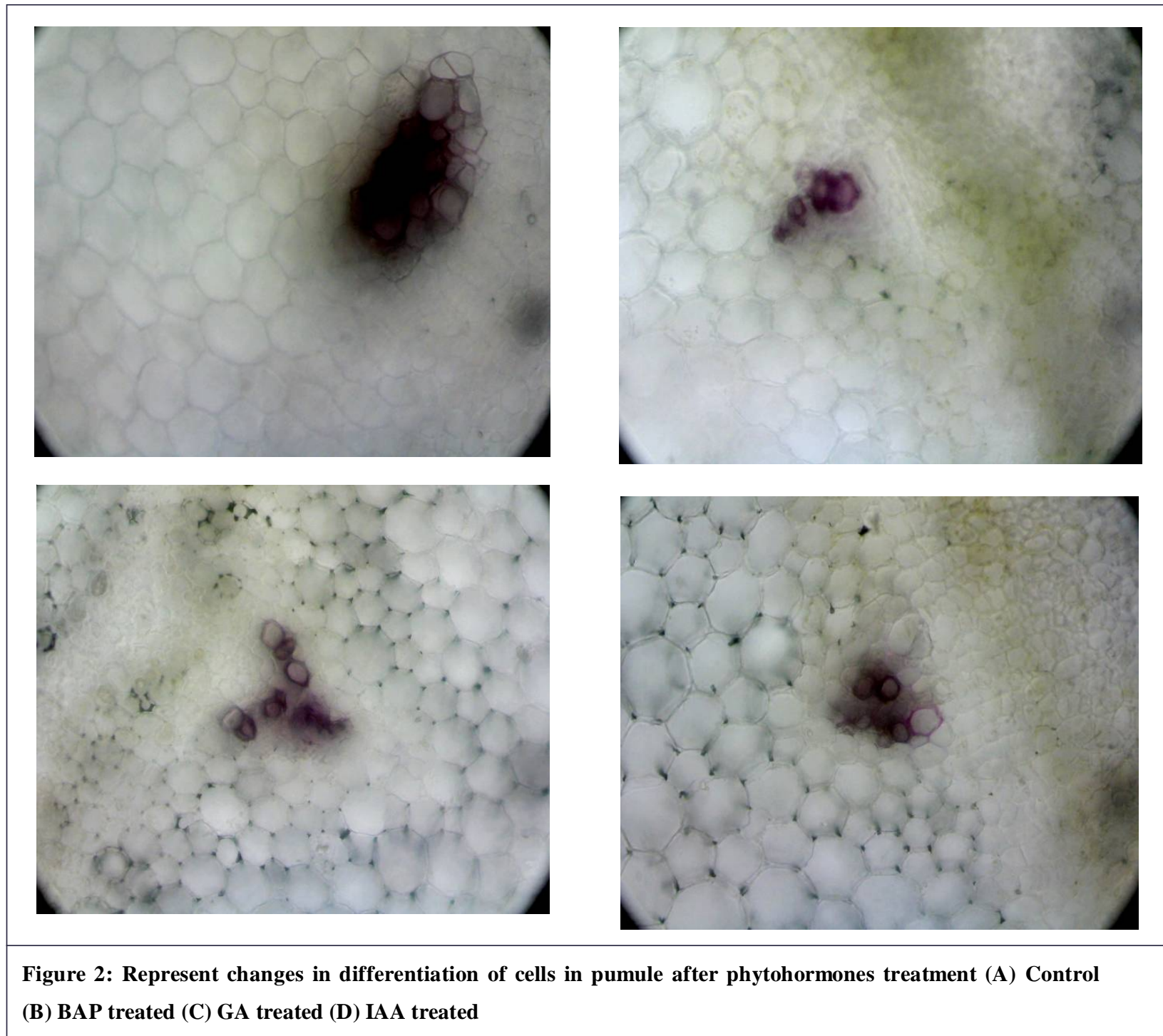

From anatomical analysis of transverse sections of radical, it was observed that the broadness of the radical was maximum in the GA treated seedlings as compared to control and other phytohormones (IAA and BAP) treated embryo. The thick epidermis layer was observed in the radical of BAP treated embryo compare to the control, IAA and GA treated embryo. The thin epidermis layer was observed in radical of IAA treated embryo as compared to the radical of control, GA and BAP treated embryo. The maximum cortex region was observed in the radical of GA treated embryo. While the 
minimum cortex region was observed in the radical of IAA treated embryo. There was a notable change in number of vascular bundles formation in radical of control and phytohormones treated embryo. There were totally six vascular bundles in T.S. of control radical, four vascular bundles in T.S. of BAP treated radical, nine vascular bundles in T.S. of GA treated radical and six vascular bundles in T.S. of IAA treated radical. In vascular bundles development, maximum xylem and phloem differentiation was observed in GA treated embryo whereas xylem and phloem differentiation was delayed in BAP treated embryo (Figure 3). The pith region was maximum in the GA treated radical While minimum pith region was observed in IAA treated radical.
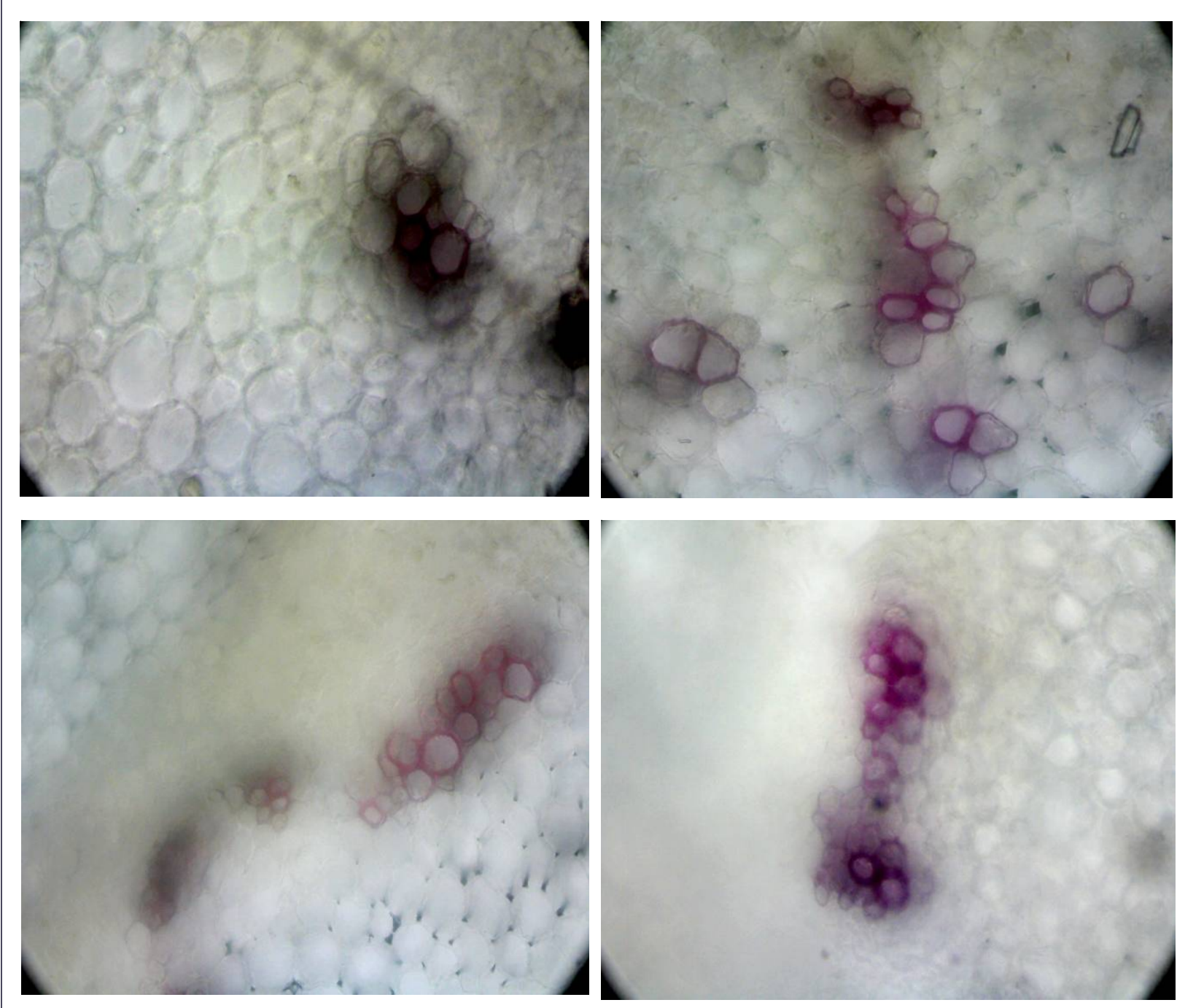

Figure 3: Represent changes in differentiation of cells in radical of embryo after phytohormones treatment

(A) Control (B) BAP treated (C) GA treated (D) IAA treated

\subsection{Change in vegetative growth of plants after phytohormones treatment}

The germinated seeds of Caesalpinia crista Lin. were grown in the soil to observe changes in the vegetative growth of plants after phytohormones treatment at an interval of one month as compared to control plants. The vegetative growth parameters such as shoot length, length of petiole, number of leaflets and area of leaflets were observed. In shoot length analysis it was observed that at initial two months IAA and BAP treated plants were having higher length as compare to control, whereas GA treated plants were shorter in length. From third month onwards up to sixth month it was observed that BAP treated plants had higher shoot length as compared to control, IAA and GA treated plants (Figure 4). In petiole length analysis, the petiole length of IAA treated plants was larger as compared to GA and BAP treated plants. The petiole length of GA and BAP treated plants was almost equivalent to each other (Figure 5). In leaflet area analysis; the leaflet area of the IAA treated plants was higher as compared to BAP and GA treated plants. GA treated plants had lowest leaflet area as compared to control and BAP treatment (Figure 6). In leaflet number analysis, it was observed that after six months the maximum number of leaflets were observed in the IAA treated plants as compared to control, BAP 


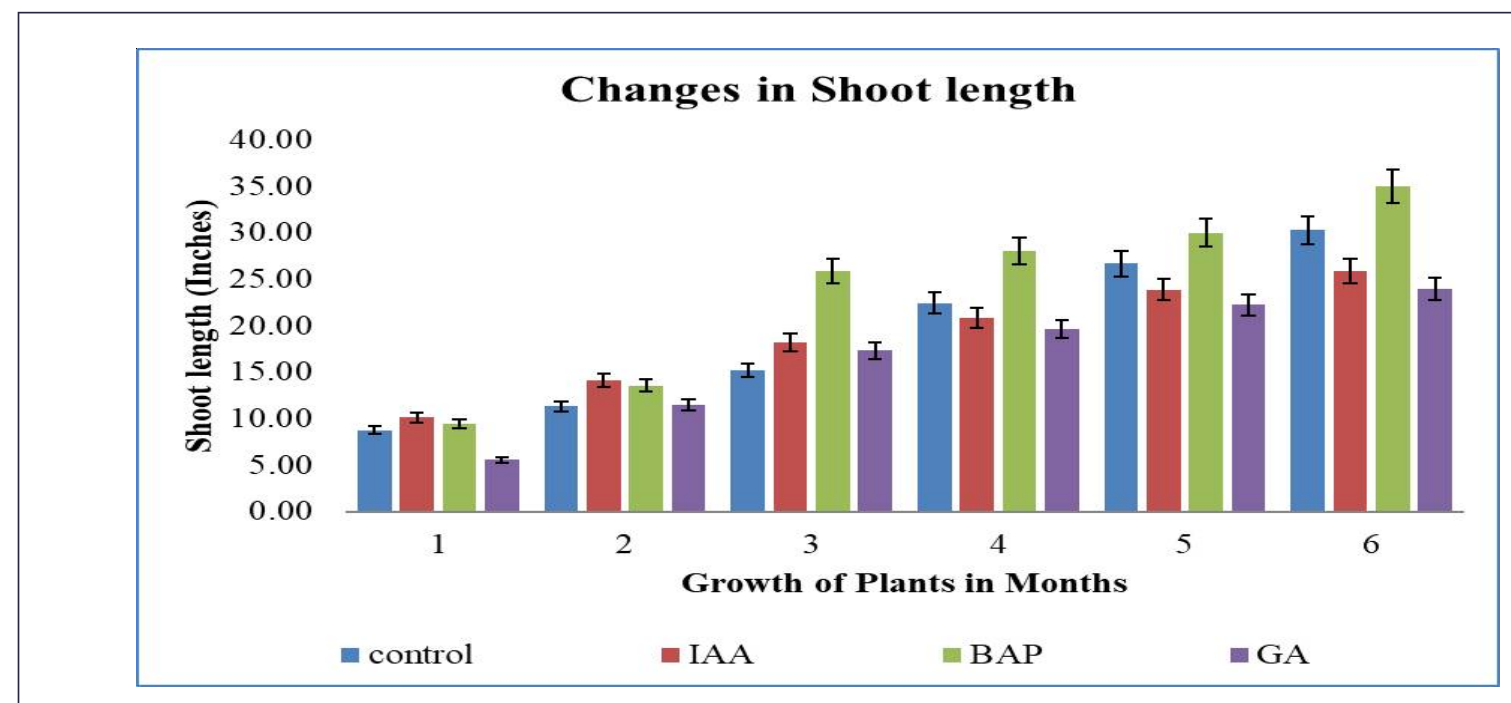

Figure 4: Represent changes in shoot length after phytohormones treatment

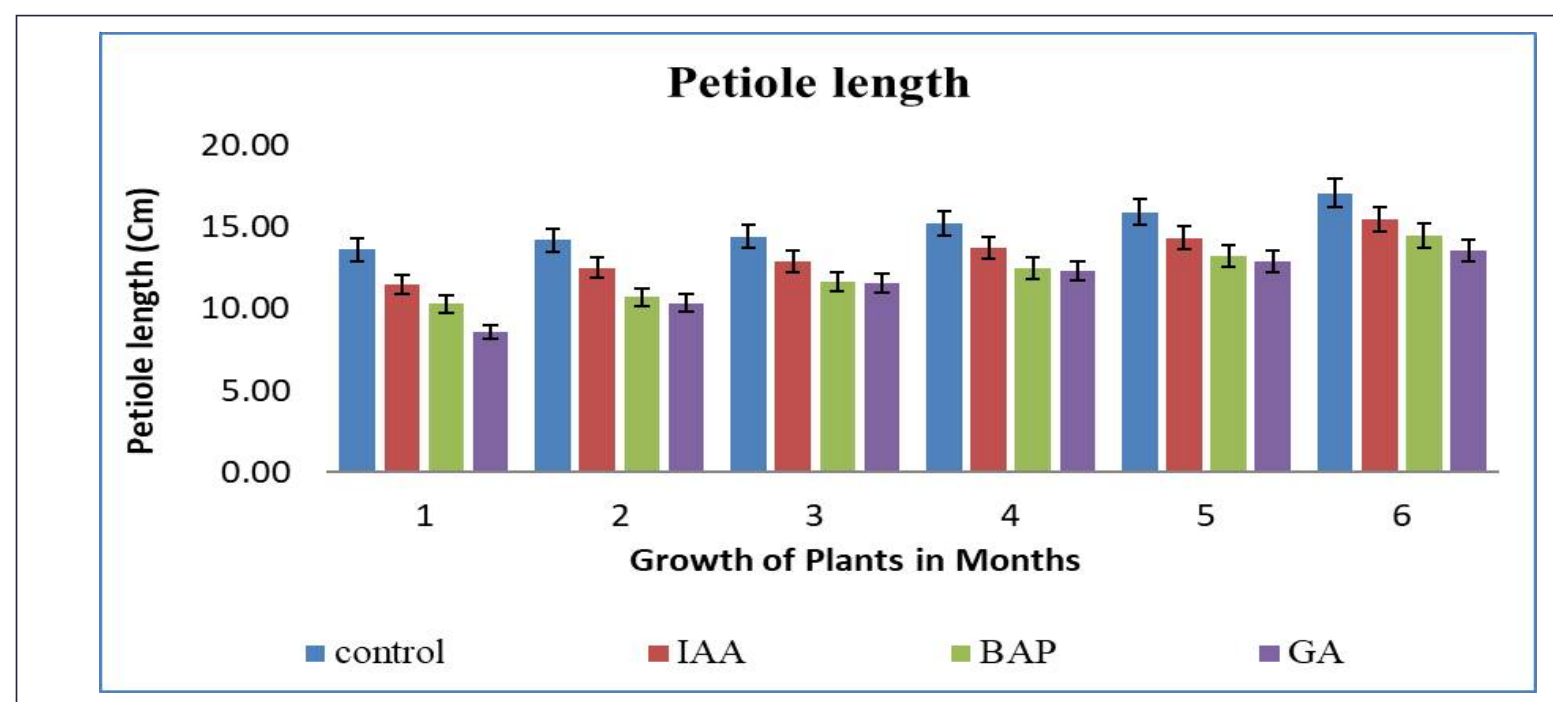

Figure 5: Represent changes in petiole length after phytohormones treatment

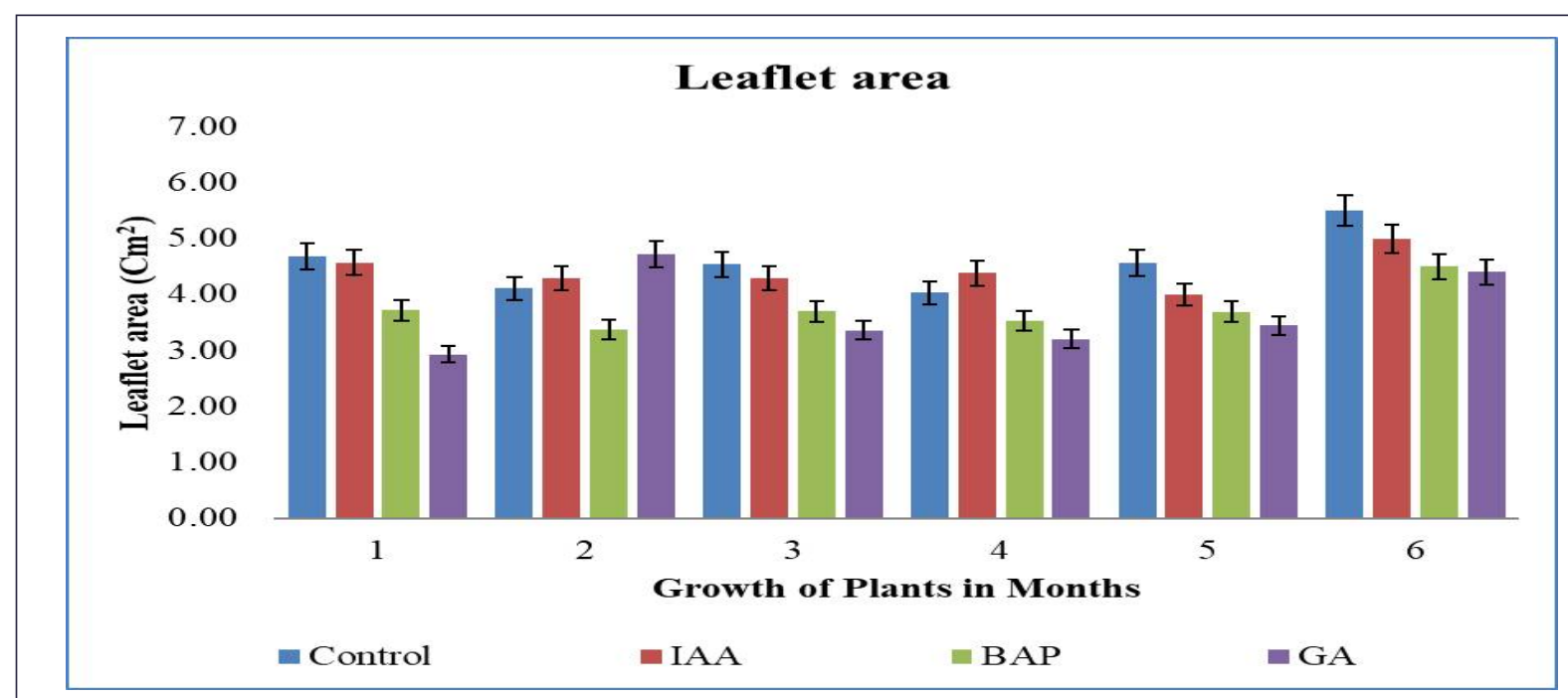

Figure 6: Represent changes in leaflet area after phytohormones treatment 
and GA treated plants. BAP and GA treated plants had equivalent number of leaflets but less number of leaflets as compared to control (Figure 7).

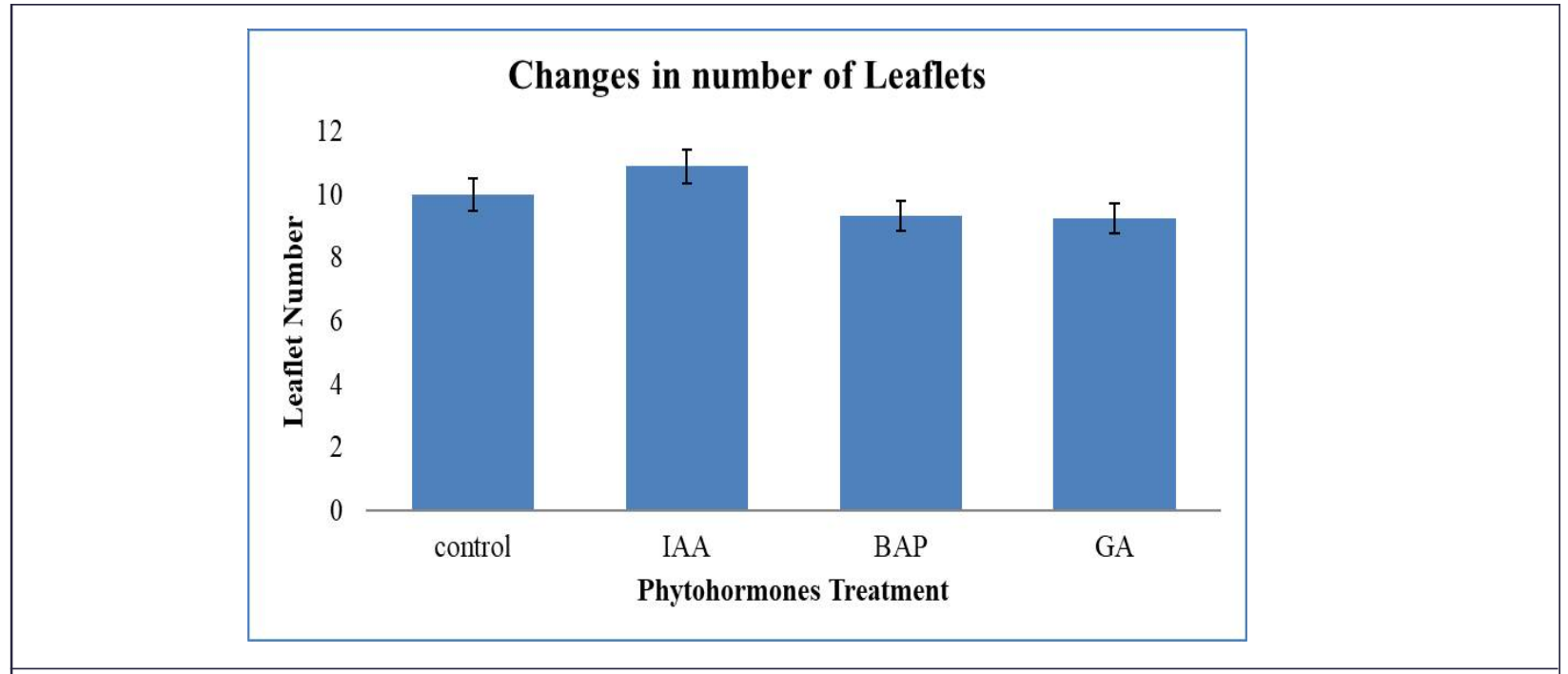

Figure 7: Represent changes in number of leaflets after phytohormones treatment

\subsection{Anatomical changes in the stem of six months old Caesalpinia crista plants}

The broadness of stem was maximum in BAP treated plants as compare to control, IAA and GA treated plants. The broadness of stem was minimum in GA treated plants as compare to control, IAA and BAP treated plants. The single layered epidermis was observed in control and phytohormones treated plants. The maximum cortex region was observed in BAP treated plants as compared to control, IAA and GA treated plants. The minimum cortex region was observed in the IAA treated plants as compare to control, BAP and GA treated plants. The pericycle was made up of sclerenchyma cells. The sclerenchyma layers were almost equal in GA and IAA treated plants but minimum in BAP treated plants. The vasculature was dictyosteller in arrangement. The sizes of vascular bundles were uniform in GA and IAA treated plants whereas in control and BAP treated plants vascular bundles were not uniform (Figure 8). There was endarch arrangement

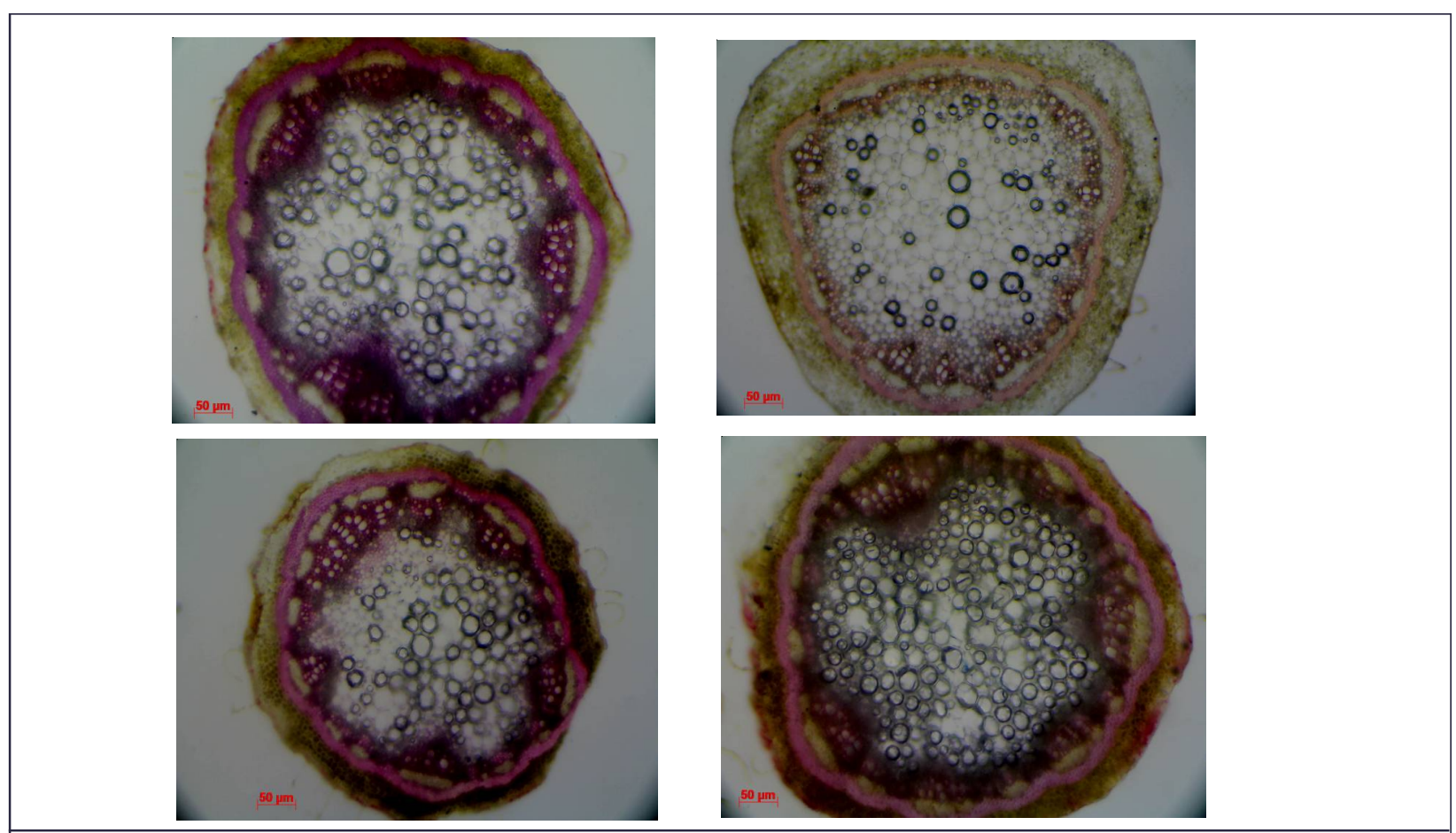

Figure 8: Represents anatomical changes in stem of Caesalpina crista Lin. plant after five months phytohormones treatment (A) Control (B) BAP treated (C) GA treatment (D) IAA treatment 
of xylem in GA and IAA treated plants whereas no such arrangement was observed in control and BAP treated plants. There were eighteen vascular bundles in control plants, twenty one vascular bundles in BAP treated plants, fifteen vascular bundles in GA treated plants and eighteen vascular bundles in IAA treated plants. Xylem tissue formation was maximum in GA and IAA treated plants as compared to control and BAP treated plants (Figure 9).

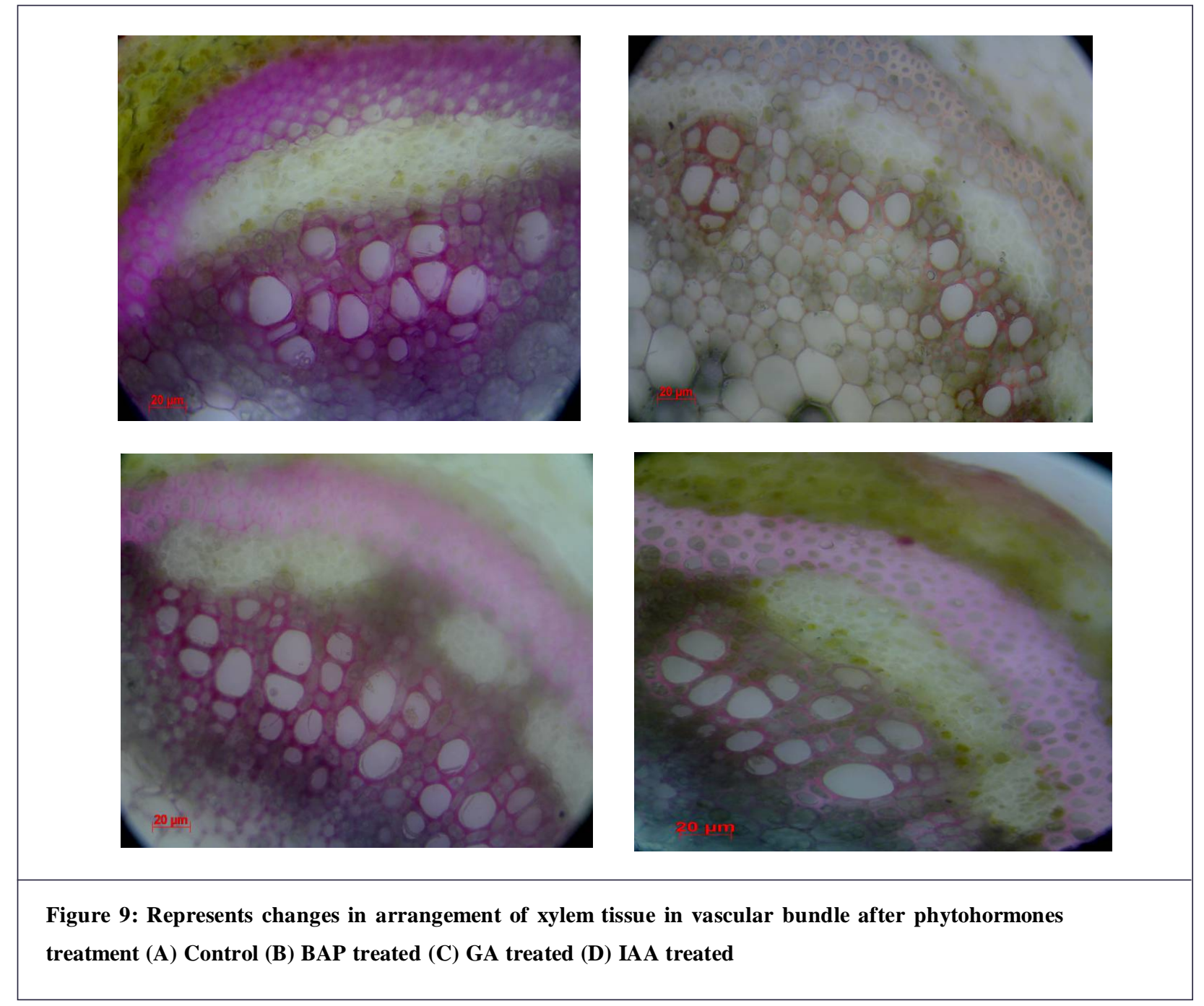

\section{Discussion}

From the growth analysis of embryo in phytohormones treated and non-treated germinated seeds, it was observed that growth of radical and pumule both were equally promoted in BAP treated seedling. The growth of radical and pumule was equal because after germination, cytokinin enhances cell division in root and shoots meristems. It regulates the formation of vascular elements and regulates leaf development (Moore, 1998; Carey, 2008). Cytokinins and gibberellins are found in actively dividing tissues of seeds; they are important to breaking dormancy after seed imbibition and allowing germination and growth of dormant embryos (Sondheimer and Galson, 1966; Brady and McCourt, 2003). In IAA treated embryos, growth of pumule was promotes whereas growth of radical delayed. Similar results were also observed by Shuai et al. (2017) which suggested that exogenous IAA represses seed germination and delays seed coat rupture and radical protrusion. Exogenous GA induces embryo cells elongation and endosperm cap weakening in germinating seeds. Inhibition of radical and pumule growth in GA treated seeds was due to release of enzymatic factors after weaking of endosperm which resulted in cell death in embryo and inhibition in growth of radical and pumule (da Silva et al., 2005).

From transverse section of radical and pumule it was observed that cortex and pith region was maximum in GA treated radical and pumule. In vascular bundles development, maximum xylem and phloem differentiation was observed in GA treated seedlings whereas xylem and phloem differentiation was delayed in BAP treated seedling. This was due to the role of cytokinin in the regulation of SAM differentiation. It was realized through the differences in the distribution of different cytokinin metabolites. Developmental changes in the concentration and localization of different cytokinin 
metabolites have been reported for the SAM of tobacco (Dewitte et al., 1999). Cytokinin by itself does not induce vascular tissues, but in the presence of IAA, cytokinin promotes vascular differentiation and regeneration (Aloni, 2010). GA regulates all processes of plant development which includes seed development and germination, stem and root growth, cell division, and flowering time (Kwon and Paek, 2016). The differentiation of xylem cells from the cambium is characteristically accompanied by a gradual accumulation of lignin, which therefore serves as a useful indicator of the progression of xylem cell differentiation. This process is controlled by the activity of several factors, including the phytohormone gibberellin (GA).

From vegetative growth analysis of phytohormones treated and non-treated plants, it was observed that BAP treated plants had higher shoot length as compared to control, IAA and GA treated plants. This suggest that cytokinin inhibits the activity of ABA on all of these processes (Carey, 2008; Kong et al., 2009), maintaining more rapid growth and, in many cases, preventing phase change of vegetative meristems to floral meristems and prolonging juvenile maturation states. The petiole length of IAA treated plants was larger as compared to GA and BAP treated plants. The leaflet area of the IAA treated plants was higher as compared to BAP and GA treated plants. the maximum number of leaflets were observed in the IAA treated plants as compared to control, BAP and GA treated plants. These is because Auxin plays significant role in leaf development (Keller, 2007) by controlling initiation of leaf primordia (Reinhardt et al., 2000), development of vascular bundles in leaf (Sieburth, 1999; Mattsson et al., 2003) and control of cell division phase during leaf expansion (Ljung et al., 2001).

From anatomical analysis of T.S. of stem of phytohormones treated and non-treated plants it was observed that, The maximum cortex region was observed in BAP treated plants. The sclerenchyma layers were almost equal in GA and IAA treated plants but minimum in BAP treated plants. The sizes of vascular bundles were uniform in GA and IAA treated plants whereas in control and BAP treated plants vascular bundles were not uniform. Xylem tissue formation was maximum in GA and IAA treated plants as compared to control and BAP treated plants. Several lines of investigation have indicated an interaction between GA (gibberellic acid) and IAA (indole-acetic acid) in xylem differentiation. Bradley and Crane (1957) showed that GA treatment stimulated cambial activity in stems of apricot spur shoots and resulted in greatly increased numbers of secondary xylem elements. Wareing (1958) postulated an interaction between GA and IAA in xylem formation resulting from cambial activity. Treatment of Lycospersicon escitlentuni L. with GA increased the length of annular-spiral elements and pitted scalariform cells, and increased the percentage of pitted xylem cells (Davis and Holmes, 1962). Soybeans treated with GA produced relatively thin walled vessel elements with greater numbers of xylem parenchyma cells (Bostrack and Struckmeyer, 1964). Odhnoff (1963) noted that xylem differentiation was initiated closer to the apex in GA-treated bean roots than in controls. Gautheret (1961) indicated the xylogenic effect of GA in tissue cultures of Jerusalem artichoke, and Netien (1957) reported the morphogenic nature of GA in cultivated xylem fragments of Jerusalem artichoke. Recently Wareing et al. (1964)have shown that the ratio of exogenous GA to IAA is important in regulating cambial activity and xylem differentiation. Bostrack and Struckmeyer (1964) have observed that Soybean plants treated with GA produced relatively thin walled xylem vessel elements with greater numbers of xylem parenchyma cells. The maximum pith region was observed in BAP treated plants whereas minimum pith region was observed in GA treated plants.

\section{Conclusion}

From the above analysis, it was concluded that Benzylaminopurine (BAP) treatment increases germination rate of Caesalpina crista seeds by promoting growth of radical and pumule in embryo as compared to Indole-Acetic acid (IAA) and Gibberellic acid (GA). It also increases shoot length of plants as compared to IAA and GA. However, IAA increases the leaf area and number of leaflets in plants as compared to BAP and GA. From the microscopic anatomical analysis of stem, it was observed that the BAP increases broadness of stem by increasing the cortex region. In the stem tissue, IAA and GA increases cambium activity and help in uniform vascular bundles formation as well as endarch xylem differentiation.

\section{Acknowledgment}

Authors are heartily thankful to Department of Biosciences, Saurashtra University, Rajkot for providing facilities to carry out present research work.

\section{References}

Aloni, R. (2010). The induction of vascular tissues by auxin. InPlant hormones (pp. 485-518). Springer, Dordrecht.

Banskota, A.H., Attamimi, F., Usia, T., Linn, T.Z., Tezuka, Y., Kalauni, S.K. and Kadota, S. (2003). Novel norcassane-type diterpene from the seed kernels of Caesalpinia crista. Tetrahedron Letters, 44(36), 6879-6882. 
Bethke, P.C., Schuurink, R. and Jones, R.L. (1997). Hormonal signalling in cereal aleurone. Journal of Experimental Botany, 48(7), 1337-1356.

Bodakhe, S.H. (2014). Anticancer study on alcoholic extract of Caesalpinia crista root bark extract. Journal of Research and Opinion, 1(4), 126-128.

Bostrack, J.M. and Struckmeyer, B.E. (1964). Effects of gibberellic acid on the anatomy of soybeans (Glycine max). American Journal of Botany. 51(6Part1), 611-617.

Bradley, M.V. and Crane, J.C. (1957). Gibberellin-stimulated cambial activity in stems of apricot spur shoots. Science, 126(3280), 972-973.

Brady, S.M. and McCourt, P. (2003). Hormone cross-talk in seed dormancy. Journal of Plant Growth Regulation, 22(1), 25-31.

Carey, Jr D.J. (2008). The effects of benzyladenine on ornamental crops.

da Silva, E.A., Toorop, P.E., Nijsse, J., Bewley, J.D., Hilhorst, H.W. (2005). Exogenous gibberellins inhibit coffee (Coffea arabica cv. Rubi) seed germination and cause cell death in the embryo. Journal of Experimental Botany, 56(413), 1029-1038.

Das, B., Srinivas, Y., Sudhakar, C., Mahender, I., Laxminarayana, K., Reddy, P.R., Raju, T.V., Jakka, N.M., Rao, J.V. (2010). New diterpenoids from Caesalpinia species and their cytotoxic activity, Bioorganic \& Medicinal Chemistry Letters, 20(9), 2847-50.

Davis, E.L. and Holmes, P.J. (1962). Morphogenetic effect of gibberellic acid on the xylem of Lycopersicon esculentum L. Phyton, 19, 31.

De Jong, M., Mariani, C. and Vriezen, W.H. (2009). The role of auxin and gibberellin in tomato fruit set. Journal of Experimental Botany, 60(5), 1523-1532.

Derkx, M.P. and Karssen, C.M. (1993). Effects of light and temperature on seed dormancy and gibberellin-stimulated germination in Arabidopsis thaliana: studies with gibberellin-deficient and-insensitive mutants. Physiologia Plantarum, 89(2), 360-368.

Dewitte, W., Chiappetta, A., Azmi, A., Witters, E., Strnad, M., Rembur, J., Noin, M., Chriqui D. and Van Onckelen, H. (1999). Dynamics of cytokinins in apical shoot meristems of a day-neutral tobacco during floral transition and flower formation. Plant Physiology. 119(1), 111-122.

Ellis, C.M., Nagpal, P., Young, J.C., Hagen, G., Guilfoyle, T.J. and Reed, J.W. (2005). Auxin response factor 1 and auxin response factor2 regulate senescence and floral organ abscission in Arabidopsis thaliana. Development, 132(20), 4563-4574.

Faiss, M., Zalubìlová, J., Strnad, M. and Schmülling, T. (1997). Conditional transgenic expression of the ipt gene indicates a function for cytokinins in paracrine signaling in whole tobacco plants. The Plant Journal, 12(2), 401-415.

Gan, S., Amasino, R.M. (1996). Cytokinins in plant senescence: from spray and pray to clone and play. Bioessays, 18(7), 557-565.

Gautheret, R. (1961). Action conjuguee de lacide gibberellique, de la cinetine et de lacide indole-acetique sur les tissus cultives in vitro, particulierement sur ceux de topinambour. Comptes rendus hebdomadaires des seances de $l$ academie des sciences. 253(14), 1381.

Grappin, P., Bouinot, D., Sotta, B., Miginiac, E. and Jullien, M. (2000). Control of seed dormancy in Nicotiana plumbaginifolia: Post-imbibition abscisic acid synthesis imposes dormancy maintenance. Planta, 210(2), 279-285.

Handa, S.S. and Kaul, M.K. (1996). Supplement to cultivation and utilization of medicinal plants. 727-739.

He, D. and Yang, P. (2013). Proteomics of rice seed germination. Frontiers in Plant Science, 4, 246.

Hilhorst, H.W. and Karssen, C.M. (1988). Dual effect of light on the gibberellin-and nitrate-stimulated seed germination of Sisymbrium officinale and Arabidopsis thaliana. Plant Physiology, 86(2), 591-597.

Jabbar, A., Zaman, M.A., Iqbal, Z., Yaseen, M. and Shamim, A. (2007). Anthelmintic activity of Chenopodium album (L.) and Caesalpinia crista (L.) against trichostrongylid nematodes of sheep. Journal of Ethnopharmacology, 114(1), 86-91. 
Jacobsen, J.V., Gubler, F. and Chandler, P.M. (1995). Gibberellin action in germinated cereal grains. In: Davies P.J. (eds) Plant Hormones. Springer, Dordrecht. https://doi.org/10.1007/978-94-011-0473-9_12

Jiang, R.W., Ma, S.C., But, P.P. and Mak, T.C. (2001). New antiviral cassane furanoditerpenes from caesalpinia $m$ inax. Journal of Natural Products, 64(10), 1266-1272.

Kalauni, S.K., Awale, S., Tezuka, Y., Banskota, A.H., Linn, T.Z. and Kadota, S. (2001). The effective Myanmar traditional medicinal plants. Ministry of Science and Technology Yangoon, Myanmar, 1, 67-78.

Kazan, K. and Manners, J.M. (2009). Linking development to defense: auxin in plant-pathogen interactions. Trends in Plant Science. 14(7), 373-382.

Keller, C.P. (2007). Leaf expansion in Phaseolus: transient auxin-induced growth increase. Physiologia Plantarum, 130(4), 580-589.

Kirtikar, K.R. and Basu, B.D. (1918). Indian Medicinal Plants Vol-3. Bishen Singh Mahendra Pal Singh and Periodical Experts.

Kong, L., Abrams, S.R., Owen, S.J., Van, Niejenhuis, A. and Von, Aderkas, P. (2009). Dynamic changes in concentrations of auxin, cytokinin, ABA and selected metabolites in multiple genotypes of Douglas-fir (Pseudotsuga menziesii) during a growing season. Tree Physiology, 29(2), 183-190.

Kshirsagar, S.N. (2011). Nootropic activity of dried seed kernels of Caesalpinia crista Linn against scopolamine induced amnesia in mice. International Journal of Pharmtech Research, 3(1), 104-109.

Kucera, B., Cohn, M.A. and Leubner-Metzger, G. (2005). Plant hormone interactions during seed dormancy release and germination. Seed Science Research, 15(4), 281-307.

Kwon, C.T. and Paek, N.C. (2016). Gibberellic acid: a key phytohormone for spikelet fertility in rice grain production. International Journal of Molecular Sciences, 17(5), 794.

Kwon, C.T., Kim, S.H., Kim, D. and Paek, N.C. (2015). The rice floral repressor Early flowering1 affects spikelet fertility by modulating gibberellin signaling. Rice, 8(1), 23.

Linn, T.Z., Awale, S., Tezuka, Y., Banskota, A.H., Kalauni, S.K., Attamimi, F., Ueda, J.Y., Asih, P.B., Syafruddin, D., Tanaka, K. and Kadota, S. (2005). Cassane-and Norcassane-Type Diterpenes from Caesalpinia c rista of Indonesia and Their Antimalarial Activity against the Growth of Plasmodium f alciparum. Journal of Natural Products, 68(5):706710 .

Ljung, K., Bhalerao, R.P. and Sandberg, G. (2001). Sites and homeostatic control of auxin biosynthesis in Arabidopsis during vegetative growth. The Plant Journal. 28(4), 465-474.

Ma, Q., Longnecker, N. and Atkins, C. (1998). Exogenous cytokinin and nitrogen do not increase grain yield in narrowleafed lupins. Crop Science, 38(3):717-721.

Mandal, S., Hazra, B., Sarkar, R., Biswas, S. and Mandal, N. (2011). Assessment of the antioxidant and reactive oxygen species scavenging activity of methanolic extract of Caesalpinia crista leaf. Evidence-Based Complementary and Alternative Medicine, 114-118.

Mattsson, J., Ckurshumova, W. and Berleth, T. (2003). Auxin signaling in Arabidopsis leaf vascular development. Plant Physiology, 131(3), 1327-1339.

Mazid, M., Khan, T.A. and Mohammad, F. (2011). Cytokinins, A classical multifaceted hormone in plant system. Journal of Stress Physiology \& Biochemistry, 7(4), 644-674.

Metzger, J.D. (1983). Role of endogenous plant growth regulators in seed dormancy of Avena fatua: II. Gibberellins. Plant Physiology, 73(3), 791-795.

Moore, G.M. (1998). Tree growth regulators: issues of control, matters of management. Journal of Arboriculture, (USA) 10-19.

Nester, J.E. and Zeevaart, J.A. (1988). Flower development in normal tomato and a gibberellin-deficient (ga-2) mutant. American Journal of Botany, 75(1), 45-55.

Netien, G. (1957). Action des gibberellines sur la culture des tissus vegetaux cultives invitro. Comptes rendus hebdomadaires des seances de lacademie des sciences. 244(22), 2732-2733. 
Odhnoff, C. (1963). The effect of gibberellin and phenylboric acid on xylem differentiation and epidermal cell elongation in bean roots. Physiologia Plantarum, 16(2), 474-483.

Patil, A.D., Freyer, A.J., Webb, R.L., Zuber, G., Reichwein, R., Bean, M.F., Faucette, L., Johnson, R.K. and Pulcherrimins, A.D. (1997). Novel diterpene dibenzoates from Caesalpinia pulcherrima with selective activity against DNA repairdeficient yeast mutants. Tetrahedron, 53(5), 1583-1592.

Peleg, Z. and Blumwald, E. (2011). Hormone balance and abiotic stress tolerance in crop plants. Current Opinion in Plant Biology, 14(3), 290-295.

Philosoph-Hadas, S., Friedman, H. and Meir, S. (2005). Gravitropic bending and plant hormones. Vitamins \& Hormones, 72,31-78.

Pospíšilová, J., Synková, H. and Rulcová, J. (2000). Cytokinins and water stress. Biologia plantarum. 43(3), 321 -328.

Reinhardt, D., Mandel, T. and Kuhlemeier, C. (2000). Auxin regulates the initiation and radial position of plant lateral organs. The Plant Cell, 12(4), 507-518.

Roitsch, T. and Ehneß, R. (2000). Regulation of source/sink relations by cytokinins. Plant Growth Regulation, 32(2-3), 359-367.

Rubinstein, B. (1963). Action of auxin on leaf abscission. Army Biological Labs Frederick Md.

Shuai, H., Meng, Y., Luo, X., Chen, F., Zhou, W., Dai, Y., Qi, Y., Du, J., Yang, F., Liu, J. and Yang, W. (2017). Exogenous auxin represses soybean seed germination through decreasing the gibberellin/abscisic acid (GA/ABA) ratio. Scientific Reports, 7(1), 1-1.

Sieburth, L.E. (1999). Auxin is required for leaf vein pattern in Arabidopsis. Plant Physiology, 121(4), 1179-1190.

Singh, D.P., Jermakow, A.M. and Swain, S.M. (2002). Gibberellins are required for seed development and pollen tube growth in Arabidopsis. The Plant Cell, 14(12), 3133-3147.

Sondheimer, E. and Galson, E.C. (1966). Effects of abscisin II and other plant growth substances on germination of seeds with stratification requirements. Plant Physiology. 41(8), 1397.

Swarup, R., Parry, G., Graham, N., Allen, T. and Bennett, M. (2002). Auxin cross-talk: integration of signalling pathways to control plant development. InAuxin Molecular Biology, Springer, Dordrecht.

Synková, H., Wilhelmová, N., Šesták, Z. and Pospíšilová, J. (1997). Photosynthesis in transgenic plants with elevated cytokinin contents. Handbook of Photosynthesis, 541-552.

Toyomasu, T., Kawaide, H., Mitsuhashi, W., Inoue, Y. and Kamiya, Y. (1998). Phytochrome regulates gibberellin biosynthesis during germination of photoblastic lettuce seeds. Plant Physiology, 118(4), 1517-1523.

Uphof, J.T. (1968). Dictionary of economic plants. Verlag Von J. Cramer, Lehre. 107.

Vanneste, S. and Friml, J. (2009). Auxin: a trigger for change in plant development. Cell, 136(6), 1005-1016.

Vanstraelen, M. and Benková, E. (2012). Hormonal interactions in the regulation of plant development. Annual Review of Cell And Developmental Biology, 28, 463-487.

Wang, S. and Fu, J. (2011). Insights into auxin signaling in plant-pathogen interactions. Frontiers in Plant Science, 2 , 74.

Wang, S., Bai, Y., Shen, C., Wu, Y., Zhang, S., Jiang, D., Guilfoyle, T.J., Chen, M. and Qi, Y. (2010). Auxin-related gene families in abiotic stress response in Sorghum bicolor. Functional \& integrative genomics, 10(4), 533-546.

Wareing, P.F. (1958). Interaction between indole-acetic acid and gibberellic acid in cambial activity. Nature, 181(4625), 1744-1745.

Wareing, P.F., Hanney, C.E. and Digby, J. (1964). The role of endogenous hormones in cambial activity and xylem differentiation. In The Formation ff Wood In Forest Trees, (pp. 323-344). Academic Press.

Wingler, A., von Schaewen, A., Leegood, R.C., Lea, P.J. and Quick, W.P. (1998). Regulation of leaf senescence by cytokinin, sugars, and light: effects on NADH-dependent hydroxypyruvate reductase. Plant Physiology. 116(1), 329-335.

Woodger, F.J., Millar, A., Murray, F., Jacobsen, J.V., Gubler, F. (2003). The role of GAMYB transcription factors in GAregulated gene expression. Journal of Plant Growth Regulation, 22(2), 176-184. 
Woodward, A.W. and Bartel, B. (2005). Auxin: regulation, action, and interaction. Annals of Botany, 95(5), 707-735.

Yang, Y.Y., Nagatani, A., Zhao, Y.J., Kang, B.J., Kendrick, R.E. and Kamiya, Y. (1995). Effects of gibberellins on seed germination of phytochrome-deficient mutants of Arabidopsis thaliana. Plant and Cell Physiology, 36(7), 12051211.

Cite this article as: Hiral H. Sojitra and Jigna G. Tank (2021). Influence of phytohormones on embryonic and vegetative growth of Caesalpinia crista. International Journal of Agricultural Sciences and Technology. 1(3), 14-26. doi: 10.51483/IJAGST.1.3.2021.14-26. 